\title{
The peripheral quantitative computed tomographic and densitometric analysis of skeletal tissue in male Wistar rats after chromium sulfate treatment
}

\author{
Marek Bieńko', Radosław Piotr Radzki', Dariusz Wolski' \\ 1 Department of Animal Physiology, Faculty of Veterinary Medicine, University of Life Sciences, Lublin, Poland \\ Bieńko M, Radzki RP, Wolski D. The peripheral quantitative computed tomographic and densitometric analysis of skeletal tissue in male \\ Wistar rats after chromium sulfate treatment. Ann Agric Environ Med. 2017; 24(3): 446-452. doi: 10.26444/aaem/74585
}

\begin{abstract}
Introduction. This study evaluates the effects of three different doses of chromium sulphate on bone density and the tomographic parameters of skeletal tissue of rats.

Materials and method. The experiment was performed on 40 male Wistar rats which received, by gavage, during 90 days, a chromium sulphate in either a daily dose of 400,600 or $800 \mu \mathrm{g} / \mathrm{kg} \mathrm{BW}$. At the end of experiment, the rats were scanned using the densitometry method (DXA) to determine the bone mineral density, bone mineral content of total skeleton and vertebral column (L2-L4) and parameters of body composition (Lean Mass and Fat Mass). The isolated femora were scanned using peripheral a quantitative computed tomography method (pQCT) for a separate analysis of the trabecular and cortical bone tissue. The ultimate strength, work to ultimate and the Young modulus of femora was also investigated by the threepoint bending test.

Results. The negative impact of chromium was observed in relation to bone tissue. All doses significantly decreased total skeleton density and mineral content, and also had impact upon the isolated femora and vertebral column. Trabecular volumetric bone mineral density and trabecular bone mineral content measured by PQCT in distal femur metaphysis were significantly lower in the experimental groups than in the control. Higher doses of chromium also significantly decreased values of ultimate strength and Young modulus in the investigated femora.

Conclusions. The results of the experiment demonstrate that chromium sulphate is dose dependent, and exerts a disadvantageous effect on the skeleton, as it decreases bone density and resistance.
\end{abstract}

\section{Key words}

rat, chromium sulfate, bone, densitometry, peripheral quantitative computed tomography, bone mineral density and content

\section{INTRODUCTION}

Chromium (Cr) is an element available in different forms, the most common being trivalent and hexavalent. The trivalent form is readily found in food, e.g. in meat, as well as in some vegetables. In people with normal health, a small quantity of chromium is needed for glucose utilization by insulin, as well as in lipid metabolism, but a deficiency of this element is extremely rare, and has been observed only in patients on long-term specific diets. Presently, chromium chloride, sulfate and their hexahydrate, picolinate and lactate trihydrate forms may be added to both food and food supplements, while chromium nitrate and chromium enriched yeast may be employed solely within food supplements. From a toxicological point of view, with regard to living organisms, the more harmful form is hexavalent chromium. This situation comes about as a result of a higher cellular uptake of hexavalent than of the trivalent form. It is very important to note that independently of dietary source, the availability level of chromium is also connected with the degree of air and water environmental contamination that the organism has experienced [1].

\footnotetext{
Address for correspondence: Marek Bieńko Ph.D., Department of Animal Physiology, Faculty of Veterinary Medicine, University of Life Sciences, Akademicka 12, 20-950 Lublin, Poland

E-mail: marek.bienko@up.lublin.pl

Received: 14 May 2016; accepted: 9 November 2016; first published: June 2017
}

When compared with soft tissue, bone has the particular feature of incorporating certain metals within its matrix. These may enter into bone turnover. Hence, skeletal tissue may potentially be a useful biological indicator of environmental contamination. In adult rats, after this element has been applied by either the oral or the intraperitoneal method, the skeletal system is generally-known as being a meaningful chromium repository [2]. It is also recognized that in humans, chromium may transfer from the mother to the bones of the developing foetus [3]. Moreover, while there is little information about long-term exposure to the trivalent form, hexavalent chromium overload is known to modify the natural bone metabolism, especially bone formation and resorption, thus having an effect on skeletal growth and condition [4-7]. These influences may have rebound as changes to some parameters, among these being density and quality of bone [8]. Such effects may be measured tomographically and densitometrically.

The aim of this study was to evaluate the effects of oral administration of different doses of chromium sulfate, on the skeletal tissue condition in Wistar rats.

\section{MATERIALS AND METHOD}

Animal procedures. All animal procedures described followed established guidelines for the care and handling of 
laboratory animals, and were approved by the Local Animal Welfare Committee in Lublin, Poland.

The study was carried out on 40 healthy male Wistar rats (Medical University, Bialystok, Poland) at the age of 2.5 months, and with an initial body weight (BW) of approximately $200 \pm 10 \mathrm{~g}$. The animals were housed in Tecniplast plastic cages (4 rats per cage), with sawdust bedding. In addition, they had ad libitum access to water and LSM Standard Rat and Mouse Diet (Agropol-Motycz, Poland). The rats were assigned to one of four groups of 10 rats each. The animals in the three experimental groups, during a 90 day period, received by gavage, a daily dose of chromium sulfate (analytical grade) (Merck, Poland), at the following rates: CR1 - $400 \mu \mathrm{g} / \mathrm{kg} \mathrm{BW}, \mathrm{CR} 2-600 \mu \mathrm{g} / \mathrm{kg} \mathrm{BW}$, CR3 - $800 \mu \mathrm{g} / \mathrm{kg}$ BW, (equals 104, 156 and $208 \mu \mathrm{g} / \mathrm{Cr} / \mathrm{kg}$ BW) dissolved in physiological saline using a rat gastric tube (Instech Laboratories, Inc. USA). The control group (CON) received, by gavage, equal volumes of physiological saline.

The body weight of these rats was determined twice a week. After 90 days, the rats were anesthetized with $\mathrm{CO}_{2}$, weighed and euthanized by cervical dislocation. Immediately after euthanasia, the animals were scanned using the densitometric (DXA) method, to determine the bone mineral density (tBMD), bone mineral content (tBMC) of total skeleton and vertebral column (L2-L4), and also to ascertain the parameters of body composition (Lean Mass and Fat Mass). Subsequently, their femora were isolated, cleaned of soft tissues and frozen for further analysis.

Densitometric analysis (DXA). The bone mineral density (tBMD), bone mineral content (tBMC) of whole body, vertebral column (L2-L4), isolated femora and the body composition (Lean Mass, Fat Mass), were established by using a Norland Excell Plus Densitometer (Fort Atkinson, WI, USA) equipped with Illuminatus DXA Software v.4.5, with Small Animal Scan option. The measurements were performed using the following parameters: scout scan speed $100 \mathrm{~mm} / \mathrm{s}$, resolution $3.0 \times 3.0 \mathrm{~mm}$; measurement scan speed $10 \mathrm{~mm} / \mathrm{s}$, resolution $1.0 \times 1.0 \mathrm{~mm}$. Region of interest (ROI) after scout scan was defined manually.

Peripheral quantitative computed tomography (pQCT). The femora were scanned by means of peripheral quantitative computed tomography (pQCT), using the Stratec XCT Research SA Plus system, with software version 6.2 C (Stratec Medizintechnik GmbH, Pforzheim, Germany). The scans (Fig. 1) were performed in the distal femur metaphysis (DFM) ( $5 \mathrm{~mm}$ from distal end) for the analysis of trabecular bone tissue, and in the middle femur of diaphysis (MFD) (50\% of bone length) for analysis of cortical bone tissue [9]. The scan line was adjusted using scout view after the initial scan of the pQCT system. Upon completion of scanning, the following parameters were determined in DFM: trabecular bone area ( $\mathrm{Tb} . \mathrm{Ar})$, trabecular bone mineral content $(\mathrm{Tb}$. $\mathrm{BMC}$ ) and trabecular volumetric bone mineral density ( $\mathrm{Tb}$. vBMD). Moreover, cortical bone area (Ct.Ar), cortical bone mineral content (Ct.BMC), cortical volumetric bone mineral density (Ct.vBMD), as well as cortical thickness (Ct.Th), periosteal (Peri.C) and endocortical (Endo.C) circumferences in MFD, were established. The analyses of trabecular bone were performed with the threshold set at $0.450 \mathrm{~cm}^{-1}$, a contour mode 2 and a peel mode 20, whereas the cortical compartment was tested with the threshold set at $0.900 \mathrm{~cm}^{-1}$, and at cortical

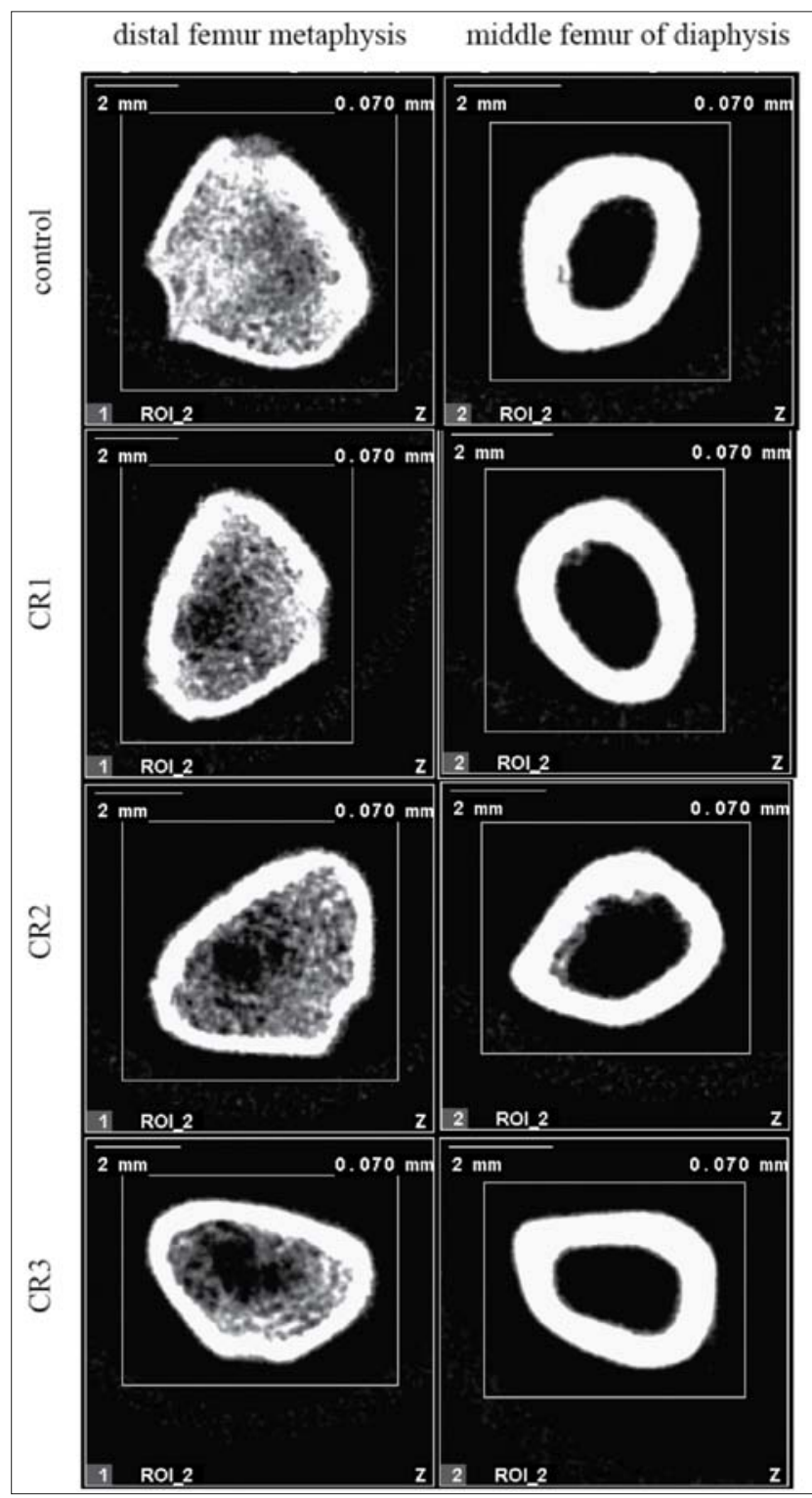

Figure 1. Sample images from pQCT scans in DFM and MFD part of femur of control and experimental groups

mode 2. Initial scan (scout view) was performed at a speed of $10 \mathrm{~mm} / \mathrm{s}$, while the CT-scan (measurement scan) speed was $4 \mathrm{~mm} / \mathrm{s}$.

Both machines were calibrated using the quality assurance phantoms (QA-Phantom), provided by the manufacturer, and performed in agreement with set procedures before every measurement series.

Mechanical testing of bone. The mechanical parameters of isolated femora were examined by way of a 3-point bending test, with the use of a ZwickRoell Z010 (ZwickRoell GmbH \& Co. KG, Ulm, Germany) universal testing machine, employing a $1 \mathrm{kN}$ measuring head, Xforce HP series. The analyzed bone were investigated as a tube model, with the external and internal diameters measured using pQCT. The bones were placed on two holders which were perpendicular to the horizontal axis, and the force was applied downward, perpendicularly to the horizontal axis, and at the midpoint of the bone. The load was increased until the bone broke. The received data were analyzed using testXpert II 3.1 software, 
and the ultimate strength $\left(\mathrm{F}_{\text {max }}\right)$, work to ultimate strength $\left(\mathrm{W} / \mathrm{F}_{\max }\right)$, and the Young modulus $\left(\mathrm{E}_{\text {mod }}\right)$ were subsequently determined.

Statistical analysis. All results were reported as mean values \pm SEM. A one-way analysis of variance (ANOVA) was used to test for significant differences among the groups. To detect significant differences between individual experimental groups, significant ANOVAs were followed by post hoc Tukey test for multiple comparisons. Differences were considered significant at $\mathrm{p}<0.05$. Analysis of significant differences was performed with the use of STATISTICA 8.0 software (StatSoft, Inc. Tulsa,TX, USA).

\section{RESULTS}

DXA parameters. The values of bone mineral density and bone mineral content of the whole body, isolated femora and L2-L4 vertebras are presented in Table 1. Chromium sulfate, also in all doses, decreased bone mineral density of the total skeleton. A significantly $(\mathrm{p}<0.05)$ negative effect was observed in the CR1, CR2 and CR3 groups, by 10.7\%, 12.6\% and $18.8 \%$, respectively (in comparison to the control), An analogous situation was observed in bone mineral content of total skeleton. In all groups (CR1, CR2 and CR3), chromium sulfate administration decreased this value (in comparison to the control group), by $19.5 \%, 21.2 \%$ and $26.4 \%$, respectively. Additionally, similar relationships, albeit, statistically insignificant, of BMD of isolated femur in all experimental groups were observed. Significantly $(\mathrm{p}<0.05)$, the lowest BMC of femur was observed in the CR3 group (by $22.2 \%$ vs. CON), whereas in the CR1 and CR2 groups, this demonstrated only a

Table 1. The effects of three doses of chromium sulfate on body mass, femur mass and length, densitometry and mechanical parameters of bone tissue

\begin{tabular}{|c|c|c|c|c|}
\hline & Control & CR1 & CR2 & CR3 \\
\hline Body mass (g) & $420,07 \pm 3,34$ & $402,8 \pm 2,73^{*}$ & $387,92 \pm 3,21^{* \#}$ & $371,45 \pm 3,48^{* \#+}$ \\
\hline Femur mass (g) & $1.026 \pm 0.075$ & $0.962 \pm 0.07$ & $1.02 \pm 0.074$ & $0.954 \pm 0.073$ \\
\hline $\begin{array}{l}\text { Femur length } \\
(\mathrm{mm})\end{array}$ & $39.49 \pm 0.65$ & $39.53 \pm 0.59$ & $39.14 \pm 0.59$ & $38.94 \pm 0.58$ \\
\hline $\mathrm{tBMD}\left(\mathrm{g} / \mathrm{cm}^{2}\right)$ & $0,159 \pm 0,0036$ & $0,142 \pm 0,0036^{*}$ & $0,139 \pm 0,0035^{*}$ & $0,129 \pm 0,0033^{*}$ \\
\hline tBMC (g) & $12,44 \pm 0,59$ & $10,011 \pm 0,51^{*}$ & $9,815 \pm 0,50^{*}$ & $9,168 \pm 0,48^{*}$ \\
\hline $\begin{array}{l}\text { Femur BMD } \\
\left(\mathrm{g} / \mathrm{cm}^{2}\right)\end{array}$ & $0.189 \pm 0.0,0059$ & $0.167 \pm 0.008$ & $0.164 \pm 0.008$ & $0.159 \pm 0.008$ \\
\hline Femur BMC (g) & $0.586 \pm 0.025$ & $0.480 \pm 0.036$ & $0.471 \pm 0.036$ & $0.456 \pm 0.035^{*}$ \\
\hline $\begin{array}{l}\text { L2-L4 BMD (g/ } \\
\left.\mathrm{cm}^{2}\right)\end{array}$ & $0.174 \pm 0.0081$ & $0.1683 \pm 0.010$ & $0.1650 \pm 0.01$ & $0.1584 \pm 0.009$ \\
\hline L2-L4 BMC (g) & $0.7284 \pm 0.11$ & $0.6473 \pm 0.066$ & $0.6346 \pm 0.065$ & $0.6092 \pm 0.062$ \\
\hline Lean mass ( $\mathrm{g}$ ) & $388.81 \pm 16.38$ & $356.57 \pm 19.93^{*}$ & $319.65 \pm 18.9^{*}$ & $303.27 \pm 12.78^{*}$ \\
\hline Fat mass (g) & $34.24 \pm 3.89$ & $31.49 \pm 3.57$ & $28.76 \pm 3.27$ & $26.70 \pm 3.03$ \\
\hline $\begin{array}{l}\text { Soft tissue } \\
\text { mass (g) }\end{array}$ & $423.05 \pm 15.81$ & $388.07 \pm 17.9$ & $348.41 \pm 19.0^{*}$ & $329.97 \pm 12.33^{*}$ \\
\hline $\mathrm{F}_{\max }(\mathrm{N})$ & $239.2 \pm 17.69$ & $217.47 \pm 3.8$ & $161.02 \pm 10.31^{* \#}$ & $148.14 \pm 9.48^{* \#}$ \\
\hline $\mathrm{E}_{\text {mod }}(\mathrm{GPa})$ & $7.76 \pm 0.50$ & $5,98 \pm 0.17^{*}$ & $5.70 \pm 0.17^{*} \dagger$ & $5,22 \pm 0.09^{*}$ \\
\hline $\mathrm{W} / \mathrm{F}_{\max }(\mathrm{Nmm})$ & $75.10 \pm 0,85$ & $79.31 \pm 0,36$ & $61.0 \pm 1,45^{* \#}$ & $56.21 \pm 1,34^{* \# \dagger}$ \\
\hline
\end{tabular}

Data are mean \pm S.E.M for 10 animals. Statistically significant differences (post hoc Tukey test for multiple comparisons) are indicated by:

vs. control $(\mathrm{p}<0.05)$

"vs. CR1 $(p<0.05)$

vs. CR2 $(p<0.05)$ tendency to lower values of bone mineral content. Chromium sulfate in all doses also had negative effects on the vertebral column. Vertebrae BMD and BMC in all experimental groups were lower, in comparison to the control, but the changes were statistically insignificant.

Tomographic measurements (pQCT). The values of pQCT analysis of cortical and trabecular bone tissue of femur are shown in Table 2 . Analyses of the cortical compartment in MFD, using pQCT techniques, revealed that no doses of chromium sulfate induced significant $(p<0.05)$ changes in Ct.vBMD values in the experimental groups, in comparison to the control. On the contrary, chromium sulfate significantly $(\mathrm{p}<0.05)$ increased values of Ct.BMC, Ct.Ar and Ct.Th in the CR2 group, in comparison to the control, by $10.2 \%, 9.9 \%$ and $5.2 \%$, respectively. Similar relationships, but statistically insignificant, were observed in the CR1 and CR3 groups. What is more, chromium sulfate given gastrically, induced a significant $(\mathrm{p}<0.05)$ increase $(9.9 \%)$ in Tot.BMC within the CR2 group, but decreased this parameter in the CR1 group (by $2.7 \%$ ). A similar tendency was observed in relation to Tot.vBMD values. In addition, analysis of trabecular bone tissue in DFM revealed that chromium sulfate significantly $(\mathrm{p}<0.05)$ decreased Tb.vBMD in all experimental groups, by $16.2 \%, 18 \%$ and $22.9 \%$ vs. CON, respectively. Beyond this, the values of Tb.BMC were significantly $(\mathrm{p}<0.05)$ lower in the CR2 and CR3 groups (by 16.5\%, 21.8\%) and insignificantly so in CR1 (by 13.7\%). Furthermore, the values of Tot.BMC

Table 2. The effects of three doses of chromium sulfate on tomographic parameters of bone tissue measured in distal femur metaphysis (DFM) and middle femur of diaphysis (MFD) part of femur

\begin{tabular}{|c|c|c|c|c|}
\hline & Control & CR1 & CR2 & CR3 \\
\hline \multicolumn{5}{|l|}{ DFM part of femur } \\
\hline $\begin{array}{l}\text { Tot.BMC (mg/ } \\
\mathrm{mm})\end{array}$ & $13.03 \pm 0.28$ & $12.66 \pm 0.20$ & $12.43 \pm 0.22$ & $11.95 \pm 0.25^{*}$ \\
\hline $\begin{array}{l}\text { Tot.vBMD (mg/ } \\
\left.\mathrm{mm}^{3}\right)\end{array}$ & $696.34 \pm 11.61$ & $688.11 \pm 10.79$ & $681.57 \pm 6.91$ & $677.14 \pm 8.25$ \\
\hline Tb.BMC (mg/mm) & $2.84 \pm 0.17$ & $2.45 \pm 0.07$ & $2.37 \pm 0.08^{*}$ & $2.22 \pm 0.09^{*}$ \\
\hline $\begin{array}{l}\text { Tb.vBMD (mg/ } \\
\mathrm{mm}^{3} \text { ) }\end{array}$ & $346.19 \pm 10.67$ & $289.95 \pm 10.13^{*}$ & $283.77 \pm 11.52^{*}$ & $266.86 \pm 4.9^{*}$ \\
\hline Tot.Ar $\left(\mathrm{mm}^{2}\right)$ & $18.28 \pm 0.34$ & $18.44 \pm 0.45$ & $18.31 \pm 0.36$ & $17.94 \pm 0.61$ \\
\hline Tb.Ar $\left(\mathrm{mm}^{2}\right)$ & $8.22 \pm 0.154$ & $8.30 \pm 0.20$ & $8.31 \pm 0.19$ & $8.07 \pm 0.27$ \\
\hline \multicolumn{5}{|l|}{ MFD part of femur } \\
\hline $\begin{array}{l}\text { Tot.BMC (mg/ } \\
\mathrm{mm})\end{array}$ & $9.12 \pm 0.13$ & $8.87 \pm 0.1$ & $10.03 \pm 0.21^{* \#}$ & $9.22 \pm 0.31$ \\
\hline $\begin{array}{l}\text { Tot.vBMD (mg/ } \\
\left.\mathrm{mm}^{3}\right)\end{array}$ & $850.63 \pm 21.37$ & $796.63 \pm 14.53$ & $855.01 \pm 13.27$ & $846.71 \pm 12.21$ \\
\hline Tot.Ar $\left(\mathrm{mm}^{2}\right)$ & $10.75 \pm 0.22$ & $11.16 \pm 0.23$ & $11.75 \pm 0.29$ & $10.91 \pm 0.42$ \\
\hline Ct.BMC (mg/mm) & $9.01 \pm 0.14$ & $8.85 \pm 0.09$ & $9.93 \pm 0.22^{* \#}$ & $9.13 \pm 0.29^{\ddagger}$ \\
\hline $\begin{array}{l}\text { Ct.vBMD (mg/ } \\
\left.\mathrm{mm}^{3}\right)\end{array}$ & $1445.88 \pm 4.27$ & $1439.13 \pm 2.43$ & $1448.74 \pm 4.54$ & $1449.15 \pm 4.56$ \\
\hline Ct.Ar $\left(\mathrm{mm}^{2}\right)$ & $6.23 \pm 0.09$ & $6.15 \pm 0.06$ & $6.85 \pm 0.14^{* \#}$ & $6.3 \pm 0.2^{\ddagger}$ \\
\hline Ct.Th (mm) & $0.652 \pm 0.01$ & $0.623 \pm 0.007$ & $0.686 \pm 0.01^{\#}$ & $0.653 \pm 0.01$ \\
\hline $\mathrm{xSSI}\left(\mathrm{mm}^{3}\right)$ & $8.16 \pm 0.14$ & $8.4 \pm 0.19$ & $9.25 \pm 0.36$ & $8.45 \pm 0.4$ \\
\hline Peri.C (mm) & $11.63 \pm 0.12$ & $11.84 \pm 0.12$ & $12.14 \pm 0.14$ & $11.69 \pm 0.22$ \\
\hline Endo.C (mm) & $7.52 \pm 0.2$ & $7.92 \pm 0.15$ & $7.83 \pm 0.15$ & $7.59 \pm 0.19$ \\
\hline
\end{tabular}

Data are mean \pm S.E.M for 10 animals. Statistically significant differences (post hoc Tukey test for multiple comparisons) are indicated by:

"vs. control $(p<0.05)$

"vs. CR1 $(p<0.05)$

${ }^{+}$vs. CR2 $(\mathrm{p}<0.05)$ 
and Tot.vBMD were also lower in all experimental groups (in comparison to the control), but the changes were statistically insignificant.

Mechanical parameters of bone tissue. The values of the analysis of the mechanical parameters of the femur are shown in Table 1. In this table, it can be seen that chromium sulfate administration significantly $(\mathrm{p}<0.05)$ reduced these. This is clearly evident in the reduction of maximum force values in the CR2 and CR3 groups (by $32.6 \%$ and $38.1 \%$ vs. CON, respectively), albeit corresponding values in the CR1 group (9.1\%) were insignificant. A similar situation was observed in the case of work to ultimate strength, in which chromium sulfate significantly $(\mathrm{p}<0.05)$ reduced the values of this parameter in the CR2 group (by 18.7\%) and the CR3 group (by $25.2 \%$ ). What is more, the values of elasticity modulus were significantly $(\mathrm{p}<0.05)$ lower in all experimental groups (in comparison to the control), by $22.9 \%$ in CR1, 26.5\% in CR2 and $32.7 \%$ in CR3.

Body mass, bone mass and length. Parameters of body composition. The results of body mass, bone mass and parameters of body composition are presented in Table 1. This shows that chromium sulfate, in all doses, decreased body weight within the experimental groups, in comparison to the control. However, the derived data were statistically insignificant. The largest drop was observed in the CR3 group (by $11,6 \%$, respectively, vs. CON), and a similar tendency was observed in relation to bone mass. In this parameter, the least value was also observed in the CR3 group (by $7.0 \%$, respectively, vs. CON). In addition, chromium sulfate significantly $(p<0.05)$ decreased soft tissue mass in both the CR2 and CR3 groups, whereas the CR1 group demonstrated a similar tendency, albeit statistically insignificantly. In all experimental groups, higher doses of chromium significantly $(\mathrm{p}<0.05)$ decreased lean mass (by $8.3 \%, 17.8 \%$ and $22.0 \%$ ), in comparison to the control group. This tendency, although demonstrating statistical insignificance, was also observed in fat mass. No changes were observed in bone length.

\section{DISCUSSION}

Bone is formed and resorbed continuously, starting from the embryo stage and continuing throughout the entire life span. This process, when evidenced in fully grown bone, is called 'bone remodeling', and is carried out by osteoblasts (bone forming cells) and osteoclasts (bone resorption cells). Dual X-ray absorptiometry (DXA) assessment is the criterion standard for the evaluation and diagnosis of bone condition. Many factors may affect bone tissue quality and bring about a decrease in BMD and BMC. The potential mechanism of the influence of chromium on the bone was described by McCarty [10]. In the presented study, rats exposed to chromium sulfate through gavage administration, revealed toxic effects on bone tissue, especially with regard to bone mineral density and bone mineral content throughout the bodies of the rat test-subjects. In the current study, a statistically $(p<0.05)$ decrease of tBMD and tBMC was observed after 90 days of chromium sulfate administration, at all applied doses. A similar situation was observed with regard to femur and vertebral column (L2-L4) bone mineral density and content.
Research carried out to-date has shown only negative effects with regard to hexavalent chromium administration [8], yet trivalent chromium administered by gavage as an inorganic salt or an organic complex is considered to be non-toxic for rats, with $\mathrm{LD}_{50}>2,000 \mathrm{mg} / \mathrm{kg} \mathrm{BW}[11]$. In the experiment undertaken by De Lucca et al. [12] involving juvenile rats, in which hexavalent chromium was given as 6.25 and $12.5 \mathrm{mg} / \mathrm{kg} / 10$ days dosages, toxic effects were noticed on bone formation. These were manifested as decreases of mandibular growth and delays in tooth eruption. Similar effects was observed in the current study. Chromium sulfate decreased tBMD and tBMC of rat mandibles in CR2 and CR3 groups (data not presented). Furthermore, in a histological study, Soudani et al. [13] observed that in the femur sections of hexavalent chromium treated rats, the proliferating chondrocytes failed to form discreet columns. Moreover, they noticed that hypertrophic differentiation and neovascularization in this region were greatly reduced. In addition, when compared to their control group, the treated rats displayed fewer, thinner, and more fragmented bone trabeculae, as well as an increase in the percentage of formation and erosive surfaces [13]. In the current study, the trabecular part of the bone tissue, as measured by pQCT, in the distal femur metaphysis, also showed significantly lower values of Tb.vBMD and Tb.BMC in the chromium sulfate treated groups. What is more, chromium sulfate administration demonstrated a negative influence on Tot.Ar and $\mathrm{Tb}$.Ar in the higher dosage groups. In addition, it must also be underlined that the Tot.vBMD and Tot.BMC in DFM results were also lower in the chromium treated rats, when compared to our control. It is also well-known that trabecular bone tissue is more sensitive (than cortical compartment) to any influences affecting bone metabolism, and the changes in trabecular bone tissue are more intensive $[14,15]$.

However, the presented study indicates, in opposition to the effect of chromium sulfate on the trabecular, that the cortical compartment of bone was more resistant to the disadvantageous influence of chromium sulfate. Herein, the values of the pQCT parameters, as measured in the MFD within the CR1 and CR3 groups, were on an approximately similar level to that of the control group. Indeed, the CR2 group alone produced significantly higher values in the Ct.BMC, Ct.Ar, Ct. Th, Tot.BMC and Tot.vBMD parameters.

It is worth emphasizing that metal-on-metal hip replacement (MOMHR), a popular alternative to conventional total hip arthroplasty for treating young and active patients with hip osteoarthritis, has been known to elevate circulating levels of chromium and cobalt ions [16]. This is because these type of implants may corrode and release chromium ions into surrounding tissues. This effect may affect bone health, by way of induced osteolysis and reducing bone formation, which could provide an explanation for the situation wherein unexplained femoral neck fractures came about during routine surgical intervention [17].

The quality of bone tissue is also associated with resistance to the fracturing which can come about when loads exceed the bone strength. Therein, trabecular thickness measured by pQCT correlates with the stiffness and bending moment of the femur, while cortical thickness correlates with breaking force [18]. Furthermore, the mechanical competence of cortical bone tissue is dependent not only on BMD, but also on the structural properties of the cortical compartment, e.g. peripheral circumference (Peri.C) and cortical area (Ct.Ar) 
(Tab. 2), as well as from cross-sectional moment of inertia (data not shown).

Studies have shown that bone fragility can be reduced by increasing bone mass, improving tissue properties, or by reorganizing bone architecture. However, in the presented study, chromium sulfate in all doses decreases the maximum force and elasticity modulus of bone tissue.

Animal and also in vitro experiments demonstrate that certain chromium forms can bring about oxidative stress and exert cytotoxic effects on bone tissue with reduced ossification, accelerated bone resorption and reduced bone formation [19]. Chromium may generate oxidative stress by producing hydroxyl radicals, superoxide anions, nitric oxide and also hydrogen peroxide [20]. Such free radical production is recognized as inducing bone-related diseases by way of suppressing bone formation and stimulating bone resorption. This process may be enhanced by the induced oxidative stress imposed by the activation of nuclear factor-kappa $\beta$ (NF$\kappa \beta)$, which is part of the RANKL-OPG axisthat regulates osteoclast differentiation, and, thus, bone resorption and remodeling [21-23]. Some observations also suggest that such oxidative stress might be involved in bone pathogenesis (osteoporosis, bone tumour) [24;25]. Bailey et al. [26], for example, observed bifurcated cervical arches in mice foetuses obtained from mothers who received chromium picolinate or picolinic acid. Moreover, in the experiment undertaken by Soudani et al. [13], rats exposed to $\mathrm{K}_{2} \mathrm{Cr}_{2} \mathrm{O}_{7}$ during the periods of late pregnancy and early postnatal had lower levels of catalase (CAT), superoxide dismutase (SOD) and the glutathione-dependent enzymes, such as glutathione peroxidase (GPx). They also noticed a decreased level of total ascorbic acid, a compound known for being an antistress agent and a powerful reducing agent, in the femurs of their test population. This effect indicates that chromium administration induced stress in the rat subjects, and that the ascorbic acid stored in their femurs was rapidly oxidized [13]. Beyond the aforementioned, it also known that antioxidant deficiency has a negative impact on bone mass [27].

Prior to 2011, chromium was reported as being an essential trace element, as it was thought to play an important role in insulin-dependent carbohydrate and lipid metabolism. However, in that year, Di Bona et al. [28] demonstrated that a low-chromium diet, in comparison to a standard sufficient diet, had no effect on body composition and glucose metabolism in lean male Zucker rats. In 2014, the European Food Safety Authority, therefore, declared that $\mathrm{Cr}$ is not an essential element for human or animal health. Still today, trivalent chromium compounds are quite often used as diet supplements for enhancing weight loss, as well as increasing lean body mass. These are also considered as being effective glycaemic control agents. Such compounds are also commonly added to animal feeds [29-32].

Research has shown that trivalent chromium may improve cell sensitivity to insulin, and thereby probably may increase the process of utilizing energy components. Moreover, it may have influence upon the protein metabolism by stimulating the intake of amino acid, and in this way, may increase protein synthesis [33]. In 1998, Cerulli et al. [34], however, described a case that revealed the toxic influence of chromium picolinate. A 33-year-old woman showed weight loss, anaemia, liver dysfunction and renal failure after ingesting chromium as a OTC nutritional supplement at a dose of 1,200-2,400 $\mu \mathrm{g} / \mathrm{day}$, ion order to enhance weight loss. A similar effect of weight loss was also observed by Onakpoya et al. [35] in patients after their self-treatment with trivalent chromium. The outcome of research into these effects is the suggestion that chromium picolinate, a popular commercial nutritional supplement, may play a role in food intake regulation by its immediate influence on the levels of trivalent chromium within the animal brain (including that of humans). Furthermore, Anton et al. [36] postulate that chromium, through the central nervous system, may regulate food intake. McLeod et al. [37] also suggest that chromium may have some influence upon the neurotransmitters regulating eating behaviour processes.

In the presented study, chromium sulfate, in all doses, significantly decreased body mass in the experimental groups, in comparison to the control. What is more, chromium sulfate definitely decreased residual parameters of body compositions, i.e lean mass, fat mass and soft tissue mass, in all the experimental groups. These results are in line with those of De Lucca et al. [12], who also observed the decrease of body mass during a 10-day experimental administration of hexavalent chromium to Wistar rats, in 6.25 and $12.5 \mathrm{mg} / \mathrm{kg} \mathrm{BW}$ doses. A similar effect was observed by Zha et al. [38]. In this work, three different forms of trivalent chromium were applied (chromium chloride, tripicolinate and nanocomposite), at dosages of $300 \mathrm{ug} / \mathrm{kg}$ $\mathrm{Cr}$, during 6 weeks of supplementation. As in the current study, they observed a decrease of fat mass, but in their work, lean mass was higher in all experimental groups, in comparison to their control. The body fat proportion was also significantly lower in group with supplementation of $300 \mu \mathrm{g} / \mathrm{kg}$ [38]. Shara et al. [39] reported that a 52-week supplementation with niacin-bound complex at the dose of $25 \mathrm{mg} / \mathrm{kg}$ diet of trivalent chromium caused decrease in body mass gain in female and male Sprague-Dawley rats, without significant changes in organ mass. Other studies have reported that chromium supplementation has no effect on body composition among women with moderate obesity [40]. On the other hand, Evans [41] reported a significant increase in lean body mass (LBM) of $1.6 \mathrm{~kg}$ in 10 college males after six weeks of resistive exercise training undertaken in conjunction with $200 \mu \mathrm{g} / \mathrm{d}$ of $\mathrm{Cr}$ picolinate supplementation. Moreover, in a second experiment in the same study, 16 trained football players showed a large increase in LBM $(2.6 \mathrm{~kg})$ and a significant decrease in percent body fat $(3.6 \%)$ after six weeks of resistive training and $\mathrm{Cr}$ supplementation. In the experiment by Hallmark et al. [42], a Cr supplemented group of untrained healthy males demonstrated an, albeit, non-significant $1.0 \mathrm{~kg}$ increase in LBM and a $1 \%$ decrease in body fat. A similar effect was seen in the study by Bahadori et al. [43], who investigated the effects of chromium yeast $(200 \mu \mathrm{g} / \mathrm{d})$ and chromium picolinate $(200 \mu \mathrm{g} / \mathrm{d})$ on LBM, in obese patients during and after mass reduction by way of a very-low-calorie diet. All groups showed comparable mass loss after eight and 26 weeks of treatment. Indeed, lean body mass, in particular, was reduced in all groups after eight weeks; however, after 26 weeks, the chromium picolinate supplemented subjects showed increased LBM, whereas the other treatment groups still had reduced lean body mass. Crawford et al. [44] also observed a statistically significant reduction in fat mass in overweight African-American women, after $600 \mu \mathrm{g}$ niacin-bound chromium supplementation, in comparison to a placebo group. What is more, Grant et al. [45] demonstrated that 43 young obese women consuming $400 \mu \mathrm{g}$ of trivalent chromium as a niacin-bound complex per 
day in combination with exercise, experienced significant mass loss over an 8-week study period. Finally, Sun et al. [46] noted mass loss and reduced levels of insulin and leptin in rats fed diets with different levels of chromium gluconate. Thus, the mechanism by which trivalent chromium has an effect upon body compositions is still unclear [33, 40, 47, 48]. It also should be mentioned that safety regarding the intake of chromium picolinate has not been established [49]. Many authors hold the opinion that chromium may reduce body mass by a number of mechanisms. Anderson [50] suggested that $\mathrm{Cr}$ increases insulin sensitivity, while Vincent [51] considered that chromium, when bound to a low molecular mass oligopeptide, can potentiate the actions of insulin at its receptor. Furthermore, Attenburrow et al. [52] thought chromium to be a factor which reduces food craving. In addition, Onakpoya et al. [53] claimed that $\mathrm{Cr}$ increases metabolic rate. In 2013, Onakpoya et al. [35] performed a systematic review and meta-analysis of randomized clinical trials on the role of chromium supplementation in the overweight and the obese. The data they derived from randomized clinical trials showed that chromium supplementation generates statistically significant reductions in body mass and percentage body fat, but the clinical effects were inconsistent, varying in the elements of individuality and time of effects; hence, there is a need for future investigation. Because of this, they suggested that clinical trials should last a minimum 16 weeks, and be undertaken with greater uniformity in the measurement methods and approaches towards evaluating body composition [35].

\section{CONCLUSIONS}

The results obtained indicate that chromium sulfate exerts a dose-dependent disadvantageous effect on bone tissue. In the current study, doses of chromium $(104,156,208 \mu \mathrm{g} / \mathrm{Cr} / \mathrm{kg}$ BW) we administered which were meaningfully lower than the known lethal dose for hexavalent chromium (46-113 mg/ $\mathrm{kg} /$ day BW for male/female rats) [1]. Such dosages brought about a lessening of total bone mineral density and mineral content within both the overall skeleton and the isolated femur. Low bone mineral density is one of the most important predictors of fracture risk. What is more, the quality of bone tissue is also dependent upon the mechanical parameters of material and their resistance to fractures. Thus, chromium sulfate exposure raises the risk of damage through decreasing the mechanical parameters of bone tissue. Future study is warranted in order to investigate the effects of chromium, and especially the trivalent form, on skeletal tissue.

\section{REFERENCES}

1. Assem L, Zhu H. Chromium. Toxicological overview. Institute of Environment and Health, Cranfield University. 2007. 1-14.

2. Witmer CM, Harris R, Shupack SI. Oral bioavailability of chromium from a specific site. Environ Health Perspect. 1991; 92: 105-110.

3. Tipton IH. The distribution of trace metals in the human body. MetalBinding in Medicine. Philadelphia: J. B. Lippincott Co; 1960.

4. Andrews RE, Shah KM, Wilkinson JM, Gartland A. Effects of cobalt and chromium ions at clinically equivalent concentrations after metalon-metal hip replacement on human osteoblasts and osteoclasts: implications for skeletal health. Bone. 2011; 49(4): 717-723.

5. Junaid M, Murthy RC, Saxena DK. Embryo- and fetotoxicity of chromium in pregestationally exposed mice. Bull Environ Contam Toxicol. 1996; 57(2): 327-334.
6. Junaid M, Murthy RC, Saxena DK. Embryotoxicity of orally administered chromium in mice: exposure during the period of organogenesis. Toxicol Lett. 1996; 84(3): 143-148.

7. Kanojia RK, Junaid M, Murthy RC. Chromium induced teratogenicity in female rat. Toxicol Lett. 1996; 89(3): 207-213.

8. Sankaramanivel S, Jeyapriya R, Hemalatha D, Djody S, Arunakaran J, Srinivasan N. Effect of chromium on vertebrae, femur and calvaria of adult male rats. Hum Exp Toxicol. 2006; 25(6): 311-318.

9. Gasser JA. Bone measurements by peripheral quantitative computed tomography in rodents. Methods Mol Med. 2003; 80: 323-341.

10. McCarty MF. Anabolic effects of insulin on bone suggest a role for chromium picolinate in preservation of bone density. Med Hypotheses. 1995; 45(3): 241-246.

11. Sreejayan N, Marone PA, Lau FC, Yasmin T, Bagchi M, Bagchi D. Safety and toxicological evaluation of a novel chromium(III) dinicocysteinate complex. Toxicol Mech Methods. 2010; 20(6): 321-333.

12. De Lucca RC, Dutrey PL, Villarino ME, Ubios AM. Effect of different doses of hexavalent chromium on mandibular growth and tooth eruption in juvenile Wistar rats. Exp Toxicol Pathol. 2009; 61(4): 347-352.

13. Soudani N, Ben A, I, Troudi A, Bouaziz H, Boudawara T, Zeghal N. Oxidative stress induced by chromium (VI) in bone of suckling rats. Toxicology and Industrial Health. 2011; 27(8): 724-7.

14. Radzki RP, Bieńko M, Pierzynowski SG. Anti-osteopenic effect of alpha-ketoglutarate sodium salt in ovariectomized rats. J Bone Miner Metab. 2012; 30(6): 651-659.

15. Radzki RP, Bieńko M, Wolski D, Lis A, Radzka A. Lipoic acid dosedependently stimulates bone formation in ovariectomized rats. Can J PhysiolPharmacol. 2016; 94(9): 947-954.

16. De Smet K, De Haan R, Calistri A, Campbell PA, Ebramzadeh E, Pattyn $\mathrm{C}$ et al. Metal ion measurement as a diagnostic tool to identify problems with metal-on-metal hip resurfacing. J Bone Joint Surg Am. 2008; 90 Suppl 4: 202-208.

17. Little CP, Ruiz AL, Harding IJ, McLardy-Smith P, Gundle R, Murray DW, et al. Osteonecrosis in retrieved femoral heads after failed resurfacing arthroplasty of the hip. J Bone Joint Surg Br. 2005; 87(3): 320-323.

18. Beaupied H, Lespessailles E, Benhamou CL. Evaluation of macrostructural bone biomechanics. Joint Bone Spine. 2007; 74(3): 233-239.

19. Kanojia RK, Junaid M, Murthy RC. Embryo and fetotoxicity of hexavalent chromium: a long-term study. Toxicol Lett. 1998; 95(3): 165-172.

20. Bagchi D, Stohs SJ, Downs BW, Bagchi M, Preuss HG. Cytotoxicity and oxidative mechanisms of different forms of chromium. Toxicology. 2002; 180(1): 5-22.

21. Schreck R, Baeuerle PA. A role for oxygen radicals as second messengers. Trends Cell Biol. 1991; 1(2-3): 39-42.

22. Schreck R, Rieber P, Baeuerle PA. Reactive oxygen intermediates as apparently widely used messengers in the activation of the NF-kappa B transcription factor and HIV-1. EMBO J. 1991; 10(8): 2247-2258.

23. Vega D, Maalouf NM, Sakhaee K. Clinical Review: The role of receptor activator of nuclear factor-kappaB (RANK)/RANK ligand/ osteoprotegerin: clinical implications. J Clin Endocrinol Metab. 2007; 92(12): 4514-4521.

24. Ozgocmen S, Kaya H, Fadillioglu E, Aydogan R, Yilmaz Z. Role of antioxidant systems, lipid peroxidation, and nitric oxide in postmenopausal osteoporosis. Mol Cell Biochem. 2007; 295(1-2): 45-52.

25. Radzki RP, Bieńko M, Filip R, Albera E, Kankofer M. Effect of Strontium Ranelate on Femur Densitometry and Antioxidative/Oxidative Status in Castrated Male Rats. Scand J Lab Anim Sci. 2009; 36(2): 193-201.

26. Bailey MM, Boohaker JG, Sawyer RD, Behling JE, Rasco JF, Jernigan JJ, et al. Exposure of pregnant mice to chromium picolinate results in skeletal defects in their offspring. Birth Defects Res B Dev Reprod Toxicol. 2006; 77(3): 244-249.

27. Ramajayam G, Sridhar M, Karthikeyan S, Lavanya R, Veni S, Vignesh RC, et al. Effects of Aroclor 1254 on femoral bone metabolism in adult male Wistar rats. Toxicology. 2007; 241(3): 99-105.

28. Di Bona KR, Love S, Rhodes NR, McAdory D, Sinha SH, Kern N, et al. Chromium is not an essential trace element for mammals: effects of a "low-chromium" diet. J Biol Inorg Chem. 2011; 16(3): 381-390.

29. Levina A, Lay PA. Chemical properties and toxicity of chromium(III) nutritional supplements. Chem Res Toxicol. 2008; 21(3): 563-571.

30. Lewicki S, Zdanowski R, Krzyzowska M, Lewicka A, Debski B, Niemcewicz M, et al. The role of Chromium III in the organism and its possible use in diabetes and obesity treatment. Ann Agric Environ Med. 2014; 21(2): 331-335.

31. Lukaski HC. Chromium as a supplement. Annu Rev Nutr. 1999; 19: 279-302. 
32. Vincent JB. Recent advances in the nutritional biochemistry of trivalent chromium. Proc Nutr Soc. 2004; 63(1): 41-47.

33. Gomes MR, Rogero MM, Tirapegui J. Considerations about chromium, insulin and physical exercise. Rev Bras Med Esporte. 2015; 11(5): $246 \mathrm{e}-250 \mathrm{e}$.

34. Cerulli J, Grabe DW, Gauthier I, Malone M, McGoldrick MD. Chromium picolinate toxicity. Ann Pharmacother. 1998; 32(4): 428-431.

35. Onakpoya I, Posadzki P, Ernst E. Chromium supplementation in overweight and obesity: a systematic review and meta-analysis of randomized clinical trials. Obes Rev. 2013; 14(6): 496-507.

36. Anton SD, Morrison CD, Cefalu WT, Martin CK, Coulon S, Geiselman $\mathrm{P}$, et al. Effects of chromium picolinate on food intake and satiety. Diabetes Technol Ther. 2008; 10(5): 405-412.

37. McLeod MN, Golden RN. Chromium treatment of depression. Int J Neuropsychopharmacol. 2000; 3(4): 311-314.

38. Zha LY, Wang MQ, Xu ZR, Gu LY. Efficacy of chromium(III) supplementation on growth, body composition, serum parameters, and tissue chromium in rats. Biol Trace Elem Res. 2007; 119(1): 42-50.

39. Shara M, Kincaid AE, Limpach AL, Sandstrom R, Barrett L, Norton $\mathrm{N}$, et al. Long-term safety evaluation of a novel oxygen-coordinated niacin-bound chromium (III) complex. J Inorg Biochem. 2007; 101(7): 1059-1069.

40. Volpe SL, Huang HW, Larpadisorn K, Lesser II. Effect of chromium supplementation and exercise on body composition, resting metabolic rate and selected biochemical parameters in moderately obese women following an exercise program. J Am Coll Nutr. 2001; 20(4): 293-306

41. Evans GW. The effect of chromium picolinate on insulin controlled parameters in humans. Int J Biosoc Med Res. 1989; 11: 163-180.

42. Hallmark MA, Reynolds TH, DeSouza CA, Dotson CO, Anderson RA, Rogers MA. Effects of chromium and resistive training on muscle strength and body composition. Med Sci Sports Exerc. 1996; 28(1): 139-144.
43. Bahadori B, Wallner S, Schneider H, Wascher TC, Toplak H. Effect of chromium yeast and chromium picolinate on body composition of obese, non-diabetic patients during and after a formula diet. Acta Med Austriaca. 1997; 24(5): 185-187.

44. Crawford V, Scheckenbach R, Preuss HG. Effects of niacin-bound chromium supplementation on body composition in overweight African-American women. Diabetes Obes Metab. 1999; 1(6): 331-337.

45. Grant KE, Chandler RM, Castle AL, Ivy JL. Chromium and exercise training: effect on obese women. Med Sci Sports Exerc. 1997; 29(8): 992-998.

46. Sun C, Zhang W, Wang S, Zhang Y. Effect of chromium gluconate on body weight, serum leptin and insulin in rats. Wei Sheng Yan Jiu. 2000; 29(6): 370-371.

47. Bennett R, Adams B, French A, Neggers Y, Vincent JB. High-dose chromium(III) supplementation has no effects on body mass and composition while altering plasma hormone and triglycerides concentrations. Biol Trace Elem Res. 2006; 113(1): 53-66.

48. Pittler MH, Ernst E. Dietary supplements for body-weight reduction: a systematic review. Am J Clin Nutr. 2004; 79(4): 529-536.

49. McAdory D, Rhodes NR, Briggins F, Bailey MM, Di Bona KR, Goodwin C, et al. Potential of chromium(III) picolinate for reproductive or developmental toxicity following exposure of male CD-1 mice prior to mating. Biol Trace Elem Res. 2011; 143(3): 1666-1672.

50. Anderson RA. Chromium, glucose intolerance and diabetes. J Am Coll Nutr. 1998; 17(6): 548-555

51. Vincent JB. Mechanisms of chromium action: low-molecular-weight chromium-binding substance. J Am Coll Nutr. 1999; 18(1): 6-12.

52. Attenburrow MJ, Odontiadis J, Murray BJ, Cowen PJ, Franklin M. Chromium treatment decreases the sensitivity of 5-HT2A receptors. Psychopharmacology (Berl). 2002; 159(4): 432-436.

53. Onakpoya IJ, Wider B, Pittler MH, Ernst E. Food supplements for body weight reduction: a systematic review of systematic reviews. Obesity (Silver Spring). 2011; 19(2): 239-244. 